\title{
Persistent Gestational Trophoblastic Disease following Ovarian Molar Pregnancy: A Case report of A Rare Entity with Review of the Literature
}

Bibechan Thapa ${ }^{1}$, Meenu Maharjan ${ }^{1}$, and Heera Tuladhar ${ }^{1}$

${ }^{1}$ KIST Medical College

June 13, 2021

\begin{abstract}
Ovarian molar pregnancy, though a very rare entity, behaves like any other molar pregnancy. After surgical management, close follow-up with Beta Human Chorionic Gonadotrophin surveillance is invariable to detect progression to persistent Gestational Trophoblastic Disease, which if develops can be treated successfully with chemotherapy.
\end{abstract}

\section{Hosted file}

CCR.docx available at https://authorea.com/users/419607/articles/526052-persistentgestational-trophoblastic-disease-following-ovarian-molar-pregnancy-a-case-report-ofa-rare-entity-with-review-of-the-literature 


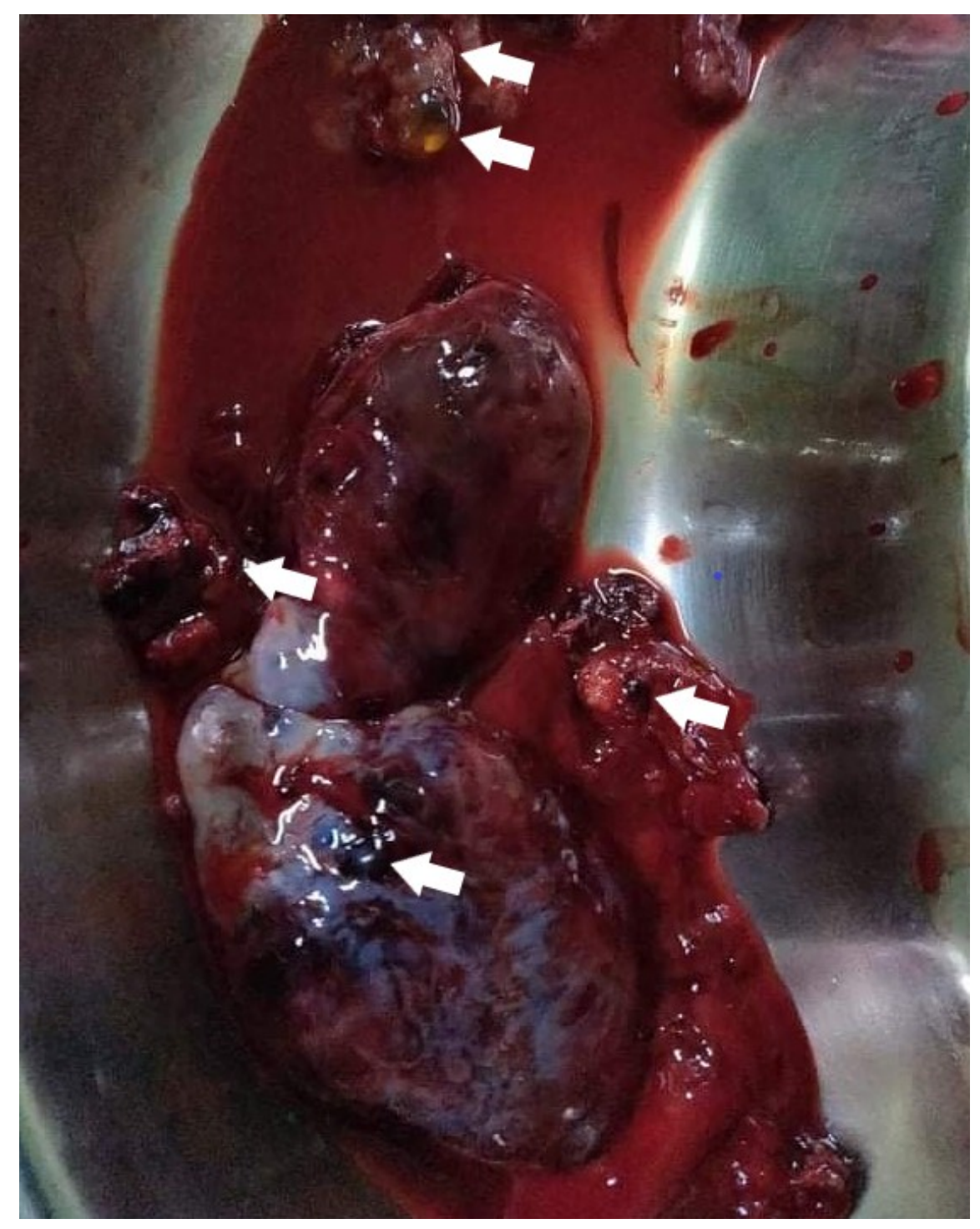



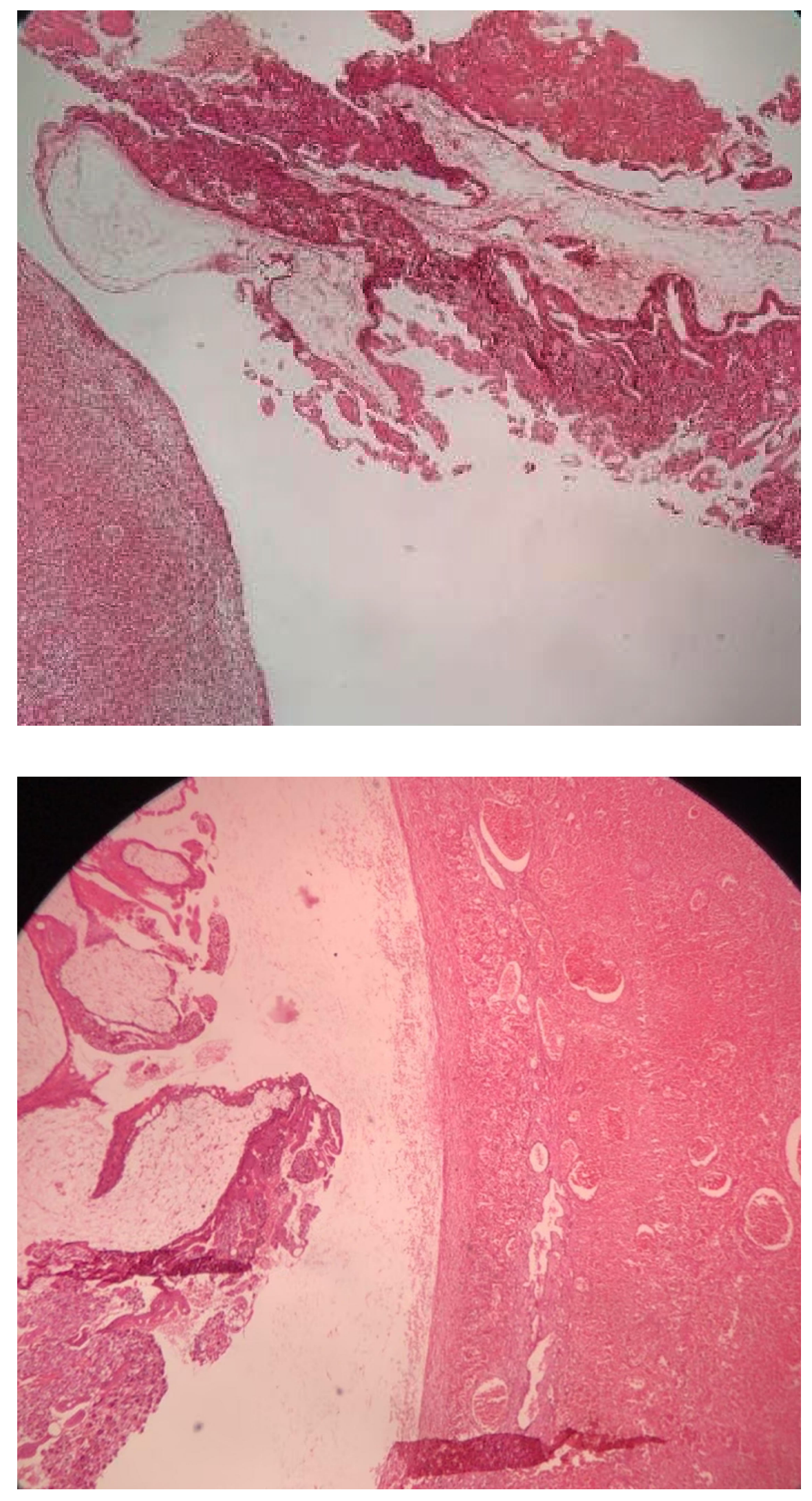


\section{Hosted file}

Figure 4. Iselectlanguage\{greek\}-\selectlanguage\{english\}hCG level (mIUml) and chemotherapy.docx available at https://authorea.com/users/419607/articles/526052-persistent-gestationaltrophoblastic-disease-following-ovarian-molar-pregnancy-a-case-report-of-a-rare-entitywith-review-of-the-literature 